ADOLFO SÁNCHEZ VÁZQUEZ: EL CONCEPTO DE CONOCIMIENTO EN EL DEBATE

MARXISTA

\author{
ADOLFO SÁNCHEZ VÁZQUEZ: EL CONCEPTO DE CONOCIMIENTO EN EL DEBATE \\ MARXISTA
}

\title{
ADOLFO SÁNCHEZ VÁZQUEZ: EL CONCEPTO DE CONOCIMIENTO EN EL DEBATE MARXISTA
}

DOI: http://dx.doi.org/10.9771/gmed.v11i3.33406

Stefan Gandler ${ }^{1}$

El filósofo mexicano-español Adolfo Sánchez Vázquez (Algeciras, Cádiz, 1915 - Ciudad de México, 2011) desarrolla en su obra epocal Filosofía de la praxis (México 1967, segunda edición, revisada y ampliada, México 1980) diferentes conceptos filosóficos del conocimiento.

Primero dirige su crítica hacia dos concepciones filosóficas del conocimiento en general: por un lado, una concepción idealista, según la cual la teoría lleva en sí misma el criterio de su verdad y, por el otro, una pragmatista o empirista, según la cual la praxis forma de manera directa e inmediata el criterio de verdad de la teoría. ${ }^{2}$ En un segundo paso dirige su crítica hacia ciertas concepciones marxistas del conocimiento que considera limitados o equivocados. En referencia a ello citamos aquí un pasaje, en donde distingue su concepción marxista del conocimiento de una pragmatista - que también dentro del marxismo tiene cierta presencia:

El conocimiento es útil en la medida en que es verdadero y no es verdadero porque es
útil, como sostiene el pragmatismo. Mientras que para el marxismo la utilidad es
consecuencia de la verdad, y no el fundamento o esencia de ella, para el pragmatismo
la verdad queda subordinada a la utilidad, entendida ésta como eficacia o éxito de la
acción del hombre, concebida esta última, a su vez, como acción subjetiva, individual
y no como actividad material, objetiva, transformadora.

Y un poco más adelante, Sánchez Vázquez escribe respecto a marxismo y pragmatismo:

¿Dónde hallar el criterio de verdad? Hay una aparente coincidencia en cuanto que uno y
otro responden: en la práctica. Pero esta apariencia desaparece de inmediato si se tiene
en cuenta que el pragmatismo y el marxismo dan un significado muy distinto a la
práctica: en un caso, acción subjetiva del individuo destinada a satisfacer sus intereses;
en el otro, acción material, objetiva, transformadora que responde a intereses sociales y 
que, considerada desde un punto de vista histórico-social, no es sólo producción de una realidad material, sino creación y desarrollo incesantes de la realidad humana. ${ }^{3}$

Dentro del desarrollo teórico del marxismo, el autor critica también diversas concepciones del conocimiento. Esta crítica debe entenderse a partir de su posición general sobre las diversas orientaciones teóricas del marxismo, partiendo de la importancia central que asigna al concepto de praxis.

\section{a) Crítica a determinadas concepciones del marxismo en general}

Cuando Sánchez Vázquez llama Filosofía de la praxis a su primera obra extensa, lo hace ante todo aludiendo a Gramsci, pero con cierta distancia crítica. En la discusión marxista, el concepto de praxis ha sufrido diversas deformaciones, es decir, análisis erróneos, que tienen su fundamento en la situación histórica concreta de cada caso. Como dos puntos focales en la discusión marxista, Sánchez Vázquez presenta al respecto a Gramsci y Althusser:

Gramsci juzga la praxis como principio unificador de los diversos ámbitos del marxismo y como categoría filosófica central. Así, se opone al marxismo de la Segunda Internacional (de fines del siglo xix), que "impregnado de las concepciones cientifistas, objetivistas y positivistas" ya no dejaba espacio a la praxis revolucionaria, como también a una metafísica materialista a la manera de Bujarin, "que restaura al viejo materialismo aderezándolo con la dialéctica”. “ Gramsci, de todos modos, sólo logra salvar la praxis (revolucionaria) al precio de despedirse de la realidad situada fuera de la praxis revolucionaria y, a la vez, del análisis científico de las relaciones sociales no plenamente acorde con esta praxis. Las implicaciones de este concepto de praxis son calificadas por Sánchez Vázquez, en las propias palabras de Gramsci, como "inmanentismo absoluto", "historicismo absoluto" y "humanismo":

La praxis es para Gramsci [...] la única realidad (de ahí su "inmanentismo absoluto"), realidad que asimismo se halla sujeta a un constante devenir, razón por la cual se identifica con la historia (de ahí también su "historicismo absoluto"). Finalmente, en cuanto que esa historia es la historia de la autoproducción del hombre, Gramsci califica su filosofía de humanismo. ${ }^{5}$

Ha de entenderse el hecho de que Gramsci denomina al marxismo 'filosofía de la praxis' a partir de esta comprensión de la praxis como punto de apoyo de éste, denominación que fue reducida erróneamente por algunos autores a una palabra encontrada casualmente para burlar la censura de la cárcel. ${ }^{6}$ Así pues, mientras Gramsci pretendía con toda razón navegar contra una fuerte corriente contemporánea de la recepción de Marx marcada por “el más vulgar reformismo y oportunismo”, 7 encalló en los bajos fondos de una subestimación del papel decisivo de los factores objetivos ("que los oportunistas elevaban al plano de lo absoluto") y con ello en el 'olvido' del carácter científico del marxismo. 8

Precisamente ese carácter científico trataron de restituirlo luego, como arma de crítica, Louis Althusser, Jacques Rancière, Pierre Macherey, Etienne Balibar y Roger Establet, con su Lire le Capital, en una época de dogmatización del marxismo y de la pretensión absoluta de definir la verdad por parte de los jefes de los partidos comunistas. (Este énfasis en el ‘carácter científico del marxismo’ significa —cabe 
agregar a lo dicho por Sánchez Vázquez-, borrar de la ciencia marxista todos los 'elementos ideológicos' y, así, navegar en contra de lo que entonces era el 'redescubrimiento' del humanismo en los escritos de Marx.) Su llamado a leer El Capital contiene:

[...] una invitación a tomar en cuenta el papel determinante de los factores objetivos representados por el mecanismo y la estructura de las relaciones capitalistas de producción, así como a abordar estas cuestiones fundamentales con el rigor conceptual que exige el carácter científico del marxismo.?

Estos autores, de todos modos, pagaron también un elevado tributo por defender el carácter científico del marxismo: "el olvido de la praxis" en la teoría misma. Si, como hace Sánchez Vázquez, se capta el concepto de praxis como concepto central de la teoría marxiana, ése es, por supuesto, un precio demasiado alto.

En esta presentación de la disputa interna marxista por la importancia de la praxis social/revolucionaria, el autor estudiado recalca que las dos 'preocupaciones' bosquejadas fueron, cada una en su tiempo, "tan legítima" la una como "saludable" la otra. ${ }^{10}$ Es cierto que no sólo al elegir el término "filosofía de la praxis", sino en la insistencia con que deplora las fallas de ambas concepciones, se permite reconocer una mayor cercanía (teórica) a Gramsci que a Althusser y a los demás autores de Lire le Capital. Sin embargo, no le interesa distribuir con pedantería, como si fuera una especie de árbitro, los puntos ganados y perdidos. Sánchez Vázquez pretende más bien insertarse él mismo en el proceso de la lucha por la formación de la teoría necesaria para la emancipación del ser humano.

Su deseo es, esquivando los defectos de ambas posturas, rescatar el "rico contenido que Marx vertió en la categoría de praxis"; rescate "al que contribuyen hoy investigadores marxistas de diferentes países, y al que aspira contribuir la presente obra." 11

\section{b) Crítica a determinadas concepciones marxistas sobre el conocimiento}

Sobre el problema particular del conocimiento, Sánchez Vázquez critica en particular dos orientaciones teóricas distintas en el marxismo. Ahí surgen de nueva cuenta momentos de la crítica a la concepción pragmatista o empirista del conocimiento.

\section{El conocimiento como resultado directo de la praxis transformadora del mundo}

El punto de partida de esta crítica es el descubrimiento de que la teoría no sólo satisface las exigencias y necesidades de una praxis ya existente, sino también las de una futura praxis en potencia. $\mathrm{Si}$ no fuera así, la teoría no podría influir sobre la praxis en su desenvolvimiento. Pero, con la investigación de esta relación entre la teoría y una praxis todavía inexistente, el análisis de la relación entre praxis y conocimiento llega a un nuevo plano. Cuando el ser humano ve la necesidad de desarrollar nuevas formas de praxis transformadoras y carece del instrumental teórico para ello, surge la situación peculiar de que la teoría necesaria es determinada por una praxis de la que aún no puede nutrirse en absoluto. ${ }^{12}$ La praxis determina aquí a la teoría como su meta, o más exactamente como "proyecto o anticipación ideal". 13 
Como ejemplos de una teoría que se adelanta ampliamente al desarrollo de la praxis que le corresponde, Sánchez Vázquez menciona la "praxis cósmica”, ${ }^{14}$ o sea, la audaz empresa del ser humano de apropiarse no sólo de la tierra sino también del 'vecino' espacio; se refiere también a la teoría general de la relatividad de Einstein y la geometría no euclidiana de Lobachevski. ${ }^{15}$ Esta circunstancia de que la praxis determina la teoría, no sólo como fundamento, fuente y criterio de la verdad, sino también como su meta, muestra "que las relaciones entre teoría y práctica no pueden verse de un modo simplista o mecánico, a saber: como si toda teoría se basara de un modo directo e inmediato en la práctica."16

Estas afirmaciones sobre las relaciones entre teoría y praxis las limita un tanto el autor, ya que “es evidente que hay teorías específicas que no se hallan en tal relación con la actividad práctica”. ${ }^{17}$ Pero, ante todo, le interesa la relación teoría-praxis en el proceso histórico-social, que tiene sus lados teórico y práctico. Con fundamento en lo constatado, Sánchez Vázquez critica un planteamiento que divide, de manera abstracta, la historia de la humanidad en una historia de la teoría y una historia de la praxis, para luego tratar de encontrar una relación directa e inmediata de dependencia entre las partes teórica y práctica de esa historia. Pero esa relación no es en modo alguno directa e inmediata, sino que se desarrolla en el curso de "un proceso complejo en el que unas veces se transita de la práctica a la teoría y otras de ésta a la práctica." 18

Para Sánchez Vázquez, la relación entre teoría y praxis no es directa e inmediata, ya que, por un lado, existen teorías que nacen para resolver directamente las dificultades y contradicciones de otras y, por otro lado, la praxis sólo es "en última instancia" fuente y meta de la teoría, y lo es como parte de un vasto proceso histórico-social. Este proceso no se puede escindir en partes que corren paralelas y aisladas entre sí, con lo que la teoría es entonces una parte, entre otras, de la práctica. ${ }^{19}$ La "autonomía relativa" de la teoría frente a la praxis, según se ha expuesto aquí, no sitúa a ambas sencillamente en un escalón en el que una y otra coexistan en recíproca independencia. Nuestro autor se atiene, además, a una primacía (si bien mediada) de la praxis frente a la teoría, pero que a su vez sólo se realiza en la unidad de la teoría y la praxis. ${ }^{20}$

La afirmación de Sánchez Vázquez de que la teoría no depende directa e inmediatamente de la praxis, desemboca en la crítica a la idea de que, al suprimirse las relaciones existentes y su inherente apariencia objetiva, al suprimirse la producción de mercancías y con ello el fetichismo de la mercancía inherente a ella, se va a revelar todo el misterio y que, de esta manera, la praxis social hará superflua la teoría allí donde ya ha llevado al comunismo. Un intérprete de Marx que lo entiende de este modo es, para Sánchez Vázquez, Kostas Axelos. ${ }^{21}$ La relación entre teoría y praxis se vuelve así del todo unilateral: la praxis fundamenta la teoría sin que ésta a su vez fundamente la praxis. Con ello, la ciencia pasa a no ser más que un "reflejo de la práctica". 22 Según esto, en esa otra sociedad la supremacía de la praxis es tal que la praxis humana y la "comprensión de la praxis"23 coinciden, es decir, ya no hay diferencia entre producción intelectual y material. "En pocas palabras, la praxis sería teórica por sí misma.”24

Adolfo Sánchez Vázquez, que en su investigación teórica del conocimiento ha concebido la unidad y al mismo tiempo la no identidad 25 entre teoría y praxis, no puede, desde luego, dejar pasar sin más ni más la afirmación de semejante primacía absoluta de la praxis, aunque ésta se limite a una sociedad 
presentada como "asociación de hombres libres" ["Verein freier Menschen"] ("que trabajen con medios de producción colectivos y empleen, conscientemente, sus muchas fuerzas de trabajo individuales como una fuerza de trabajo social"). ${ }^{26}$ Las fronteras entre la teoría y la praxis son movibles y relativas, y la relación entre ambas es sumamente fuerte, pero ambas exigen, para poder desarrollarse, una relativa autonomía recíproca. Por lo tanto, la frontera entre ellas nunca puede desaparecer del todo. Del papel determinante que la praxis tiene para la teoría como fundamento, meta y criterio de verdad del conocimiento, no se puede llegar a la conclusión formulada por Axelos, que totaliza la praxis, en el sentido de un automatismo que lleva a un conocimiento general, sin intervención de la teoría, como consecuencia directa de la liberación social. ${ }^{27}$

Se puede entender aquí a Sánchez Vázquez de la siguiente manera: la confluencia de teoría y praxis en una sociedad comunista significaría algo así como el final del desarrollo humano-social, que prospera en la zona de tensión entre esas dos expresiones vitales del ser humano (la capacidad teórica y la capacidad práctica). En consecuencia, en posiciones como las que critica Sánchez Vázquez en Axelos, la sociedad comunista es vista finalmente como una entidad en la que ya no hay problemas fundamentales. Pero esto contradice la concepción de Marx, que no vinculaba a la revolución proletaria el final de la historia sino su comienzo propiamente dicho. Esta revolución no resolvería de golpe todos los problemas de los seres humanos, sino que sólo eliminaría esa contradicción antagónica fundamental que impide una solución seria de otros muchos problemas. Con la conclusión de la "prehistoria de la sociedad humana", 28 los seres humanos deben ingresar precisamente en la organización consciente de su forma social. Con la superación de la mercancía — y con esto, de su carácter fetichista—, se quita del paso una colosal barrera del conocimiento; pero Marx no habla en ninguna parte de un tal automatismo como el antes mencionado que, a fin de cuentas, haría superfluo hasta el pensamiento mismo. Un simple regreso al estado natural algo así sería casi un automatismo del conocimiento que evoca al instinto- no era el deseo de Marx.

Está en este contexto fuera de discusión — también para el autor que aquí analizamos- que la ciencia y la filosofía ${ }^{29}$ - la cual Sánchez Vázquez a diferencia de la "ciencia positiva" no quiere dejar atrás- deberían transformarse a sí mismas en otra sociedad y, por ejemplo, suprimir su distanciamiento simplón frente a los no especialistas.

\section{Crítica de la concepción del conocimiento como algo alcanzado exclusivamente dentro de la teoría}

El rechazar la negación de la relativa autonomía de la teoría, es decir, el no aceptar la presunción de la praxis como generadora de conocimiento por sí sola, que haría superflua la teoría (o filosofía), por lo menos a la larga, puede, sin embargo, llevar a una 'solución' igualmente falsa del problema teoría-praxis, solución que tiene algo en común con la criticada anteriormente, a saber: que también en ella se concibe la unidad de teoría y praxis como su identidad sin más. Pero, si en la citada concepción casi empirista del conocimiento, esa identidad se produce al hacer absoluta la primacía de la praxis, es decir, si la teoría, allí donde es más que una técnica teórica, se vuelve superflua paso a paso a través de la praxis progresiva, en 
especial la revolucionaria, entonces, en la presunción ahora criticada, se destruye la primacía de la praxis; la teoría se vuelve autónoma de ella, no sólo relativa sino plenamente. Esta concepción llega hasta el punto en que la teoría, que ostenta en sí misma el criterio de verdad, traspasa la frontera de la praxis al convertirse ella misma en praxis. En consecuencia, ya no se plantea el problema de que el fundamento, la meta y el criterio de verdad de la teoría puedan estar asentados fuera de ella.

Si en la concepción criticada anteriormente la teoría fue 'engullida' por la praxis, esta vez la primera 'carcome' a la segunda. Ella misma se vuelve una forma de praxis entre otras con las que puede coexistir. Como autor que sostiene tal posición teórica del conocimiento, Sánchez Vázquez menciona al marxista francés Louis Althusser. ${ }^{30}$

Para poder seguir a Sánchez Vázquez en su crítica a la concepción althusseriana del conocimiento, conviene puntualizar que ambos teóricos han desarrollado diferentes conceptos de la praxis y, por ello, también diferentes conceptos de la teoría. Nuestro autor critica el concepto de praxis teórica o, como él escribe aquí, “práctica’ teórica”. ${ }^{31}$ Es cierto que la actividad teórica ${ }^{32}$ —este concepto es más apropiado según nuestro autor - transforma ideas, conceptos y crea un "tipo peculiar de productos que son las hipótesis, teorías, leyes, etcétera"; pero hace falta, además, el lado material de la materia prima, de la actividad y del resultado, que le corresponde esencialmente a la praxis. ${ }^{33}$ Por lo tanto, dice Sánchez Vázquez, "no consideramos que sea legítimo hablar de praxis teórica". ${ }^{44}$ Las diferencias entre teoría, entendida como producción de metas y conocimientos, y praxis impiden introducir tal conceptualización.

Por su objeto, fines, medios y resultados, la actividad teórica se distingue de la práctica. Su objeto o materia prima son las sensaciones o percepciones —es decir, objetos psíquicos que sólo tienen una existencia subjetiva-, o los conceptos, teorías, representaciones o hipótesis que tienen una existencia ideal. El fin inmediato de la actividad teórica es elaborar o transformar idealmente, no realmente, esa materia prima, para obtener como productos, teorías que expliquen una realidad presente o modelos que prefiguren idealmente una realidad futura. ${ }^{35}$

Esta actividad teórica es de indispensable importancia para la praxis transformadora del mundo, en la medida en que impulsa el saber necesario para ello y traza metas que anticipan idealmente esta transformación. Pero, a pesar de ello, la actividad teórica deja intacta la realidad existente. ${ }^{36}$ Es cierto que la actividad teórica también transforma algo, pero su objeto no es la realidad en sí, sino que lleva a cabo transformaciones ideales (lo cual también determina su resultado): "paso de una hipótesis a una teoría, y de ésta a otra teoría más fundada".37

Los medios de su transformación son igualmente muy distintos de lo que Sánchez Vázquez concibe como praxis. Sus operaciones son "operaciones mentales: abstraer, generalizar, deducir, sintetizar, prever, etc.". ${ }^{38}$ Estas operaciones, si bien presuponen un "sustrato corpóreo" y el funcionamiento del sistema nervioso, siguen siendo, a pesar de ello, subjetivas o psíquicas, "aunque puedan tener manifestaciones objetivas". 39

Aquí se plantea la pregunta de qué es exactamente lo que el autor concibe como esas "manifestaciones objetivas": ¿se refiere a las líneas de la tinta sobre el papel con las que se fijan las teorías en forma escrita, o a las ondas sonoras con las que son comunicadas a un contemporáneo o se refiere a otras formas de propagación, por ejemplo la edición y distribución de una revista político-teórica? 
En su distanciamiento del concepto de 'praxis teórica', Sánchez Vázquez rechaza que la elaboración y el ulterior desarrollo de las teorías puedan entenderse en sí mismos como 'praxis'; pero en los pasos necesarios de mediación entre teoría y praxis ¿dónde ve él exactamente la frontera que separa a una de la otra? Él mismo afirma la necesidad de esos pasos intermedios de mediación cuando escribe:

Entre la teoría y la actividad práctica transformadora se inserta una labor de educación de las conciencias, de organización de los medios materiales y planes concretos de acción; todo ello como paso indispensable para desarrollar acciones reales efectivas. ${ }^{40}$

Pero ¿a quién se deben adjudicar esos pasos intermedios, a la teoría o a la praxis? O, si se adjudican a un tercero, ello resolvería sólo en apariencia el problema de la delimitación exacta entre teoría y praxis, al transferirlo al doble problema recién surgido sobre por dónde corren a su vez las líneas fronterizas del elemento intermedio y, a su vez, en qué relación exacta se halla éste frente a la teoría y a la praxis, y si introducirlo no acarrea un mayor distanciamiento de ambas entre sí.

La pregunta que nos surge aquí para Sánchez Vázquez podría formularse de la siguiente manera: ¿cómo estima el filósofo su propio papel, su propia actividad, cuando, por ejemplo, escribe en un diario mexicano artículos político-teóricos, dirige una colección de libros con temas sociológicos y filosóficos, o cuando en la guerra civil española editaba un periódico de la Juventud Comunista en Madrid, así como un periódico para soldados en el frente -lo que, además de la redacción de textos, también implica una permanente búsqueda de imprentas en nuevos lugares-? ¿Se trata aquí de teoría (que para él, como se ha dicho, además de la producción de conocimiento, también abarca la de metas prácticas) y su inherente "sustrato corpóreo" y "manifestaciones objetivas", ${ }^{41}$ o de praxis; o del tal paso intermedio, el que, sin embargo, no aborda con más detalle?

Así pues, mientras Sánchez Vázquez critica, por un lado, el concepto de 'praxis teórica', partiendo de su diferenciación de concepto entre teoría y praxis y concluye que la teoría sólo puede ser concebida como forma de praxis cuando se estira el concepto de praxis "hasta borrar toda diferencia específica con el de actividad en general", ${ }^{2}$ también critica el cuestionable concepto desde otro lado; recurre directamente a dos textos de Marx para fundamentar su rechazo de la concepción de una 'praxis teórica': las Tesis sobre Fenerbach y la Introducción general a la crítica de la economía politica.

En la primera Tesis sobre Feuerbach, Marx critica que éste se limite a la relación contemplativa del ser humano ante la realidad y desatienda el lado práctico. De ahí, Sánchez Vázquez interpreta que Marx está efectuando una contraposición entre contemplación, vale decir teoría, y praxis, estableciendo la frontera o límite entre ambas. ${ }^{43}$ Así, en la undécima Tesis sobre Feuerbach, Marx distingue entre una filosofía orientada a la praxis transformadora y otra restringida a la pura interpretación del mundo. El autor examinado concluye también de aquí que Marx entiende la teoría y la praxis como dos formas de comportamiento humano claramente delimitadas entre sí: "Esta contraposición de contemplación (teoría) y práctica demuestra que Marx, lejos de admitir la teoría como una forma de praxis, establece por el contrario una distinción entre una y otra." 44

En la Introducción general a la crítica de la economía política, Marx establece una distinción entre lo concreto real y lo concreto pensado, y caracteriza la actividad teórica intelectual como el proceso de 
ascenso de lo abstracto a lo concreto. 45 Este proceso ocurre en el pensamiento y contiene la "reproducción espiritual del objeto real bajo la forma de lo concreto pensado".46 Marx aclara en forma inequívoca que en esa actividad, en esa reproducción intelectual, se trata de una producción que no crea nada real, es decir, que no transforma la realidad.

También aquí, Sánchez Vázquez vuelve a ver una clara diferenciación marxiana entre pensamiento y "actividad práctica material, adecuada a fines, que transforma el mundo" (es decir, entre teoría y praxis); ${ }^{47}$ una diferenciación, pues, que prohibe categóricamente hablar de algo como 'praxis teórica'.

El concepto criticado de praxis teórica va acompañado de una concepción del conocimiento que, aun cuando defendida en su momento por autores marxistas, Sánchez Vázquez la designa como "la vieja tesis idealista". ${ }^{48}$ Esta concepción del conocimiento comete (aparte del mencionado paralelismo) el error exactamente opuesto al de la concepción anteriormente criticada, cuasi empirista, existente dentro del marxismo, que da a la praxis revolucionaria un carácter absoluto como creadora y fundadora del conocimiento y subestima o niega del todo la importancia de la teoría emancipadora que acompaña a la praxis revolucionaria. Esa concepción, que es marxista pero a la vez cuasi idealista, niega la praxis como criterio de la verdad. Nuestro autor critica tal concepción como una reacción exagerada en contra de la subestimación que ha recibido la teoría en el seno del marxismo o de los partidos comunistas. "Pero esta imposibilidad de la práctica de determinar por sí sola si algo es verdadero o falso, es decir, sin la mediación de la teoría, no significa que ella no sea, en última instancia, el criterio de verdad". ${ }^{49}$

El tipo de concepciones aquí criticadas, terminan por buscar el criterio de la verdad mediante la revisión de los propios procesos teóricos, en la constitución interna de la teoría o en su concordancia lógica. Ésa es, desde luego, la forma idealista de averiguar la verdad, forma que no capta el factor de la praxis objetiva como elemental en el propio proceso del conocimiento. ${ }^{50}$ Ésa es exactamente la posición que Marx reprobó al dar al concepto de praxis el papel central en su obra.

Sánchez Vázquez formula aquí su crítica en general contra el concepto de 'praxis teórica', pero en sus notas al pie de página menciona, como ya se ha dicho, una y otra vez a Althusser como el teórico a cuya conceptualización va dirigida la crítica. ${ }^{51} \mathrm{El}$ reclamo de ser idealista que ha expresado contra la estudiada concepción del conocimiento, se debe entender, desde luego, en referencia a Althusser. En otra nota a pie de página, sin embargo, Sánchez Vázquez relativiza esta crítica a Althusser. Le concede a su contemporáneo que su teoría se distingue de los enfoques idealistas en la medida en que está consciente de que las ideas o la teoría por sí mismas no ocasionan una transformación del mundo real.52 Para ello se refiere a un texto de Althusser publicado en Cuba. ${ }^{53}$ Sánchez Vázquez subraya aquí que a Althusser le interesa destacar las peculiaridades de lo que llama 'praxis teórica' y lo que “corresponde en gran parte no totalmente, puesto que nosotros incluimos también en ella la producción de fines - a lo que nosotros [i.e. Sánchez Vázquez] denominamos actividad teórica", 54 sin intención alguna de equipararla a la praxis material, objetiva.

Pero con ello no se ha retirado la crítica, sino que sólo se ha modificado: el autor discutido hasta aquí cierra esta importante nota con una nueva formulación de su crítica al concepto de la 'praxis teórica': 
“Creemos, por ello, que el empleo del término 'práctica' allí donde no se opera esa transformación objetiva y real induce a confusión, pese al empeño en diferenciar sus formas específicas". ${ }^{55}$

El impulso, de aportar desde las concepciones filosóficas más elaboradas elementos para el desarrollo de una reflexión de alto nivel de los problemas de nuestro tiempo, ha sido y sigue siendo lo que ha guiado toda la producción filosófica de Adolfo Sánchez Vázquez desde su Filosofía de la praxis. Sus aportaciones siguen siendo esto: una crítica, tajante y solidaria a la vez, de las ideas y realidades que crean la conciencia tendencialmente falsa en nuestra sociedad, y así habría que entender su críticas a ciertas otras concepciones marxistas de la conciencia humana actual: no como un ejercicio soberbio para demostrar la superioridad del propio pensamiento, sino como un intento de aportar, desde el debate intra-marxista, elementos centrales para una Teoría crítica y marxista desde las Américas. Esta teoría podría, siguiendo las ideas que tuvo Sánchez Vázquez, preparar el camino para evitar - en la medida de lo posible- la repetición de los viejos errores políticos y teóricos de la izquierda de América Latina y del mundo, que una y otra vez se ha auto limitado con ello en su lucha contra los proyectos políticos y sociales más represivos, exploradores y excluyentes.

\section{Notas:}

${ }^{1}$ Facultad de Ciencias Políticas y Sociales. ORCID: Email: stefan.gandler@gmail.com

2 Adolfo Sánchez Vázquez, Filosofía de la praxis, segunda edición, corregida y aumentada, México, Grijalbo, 1980 (col. Teoría y praxis, núm. 55), p. 160. Sobre la crítica de Sánchez Vázquez a una concepción pragmatista del conocimiento, véase además: Ibid., Segunda parte: "Algunos problemas en torno a la praxis", capítulo II: "Unidad de la teoría y la práctica", subcapítulo: "El punto de vista del 'sentido común'. El pragmatismo", pp. 270-274.

Sánchez Vázquez menciona en su crítica como ejemplo de un autor pragmatista a William James y sus obras: Philosophical conceptions and practical results, 1898; Pragmatism. A new name for some old ways of thinking, 1909; edición posterior, Londres, 1928; y, The meaning of truth, 1909; edición posterior. En: William James, The Works. Cambridge, Mass., 1975, tomo 2, "The meaning of truth". (Adolfo Sánchez Vázquez, Filosofía de la praxis, loc. cit., p. 272, nota 3.).

3 Adolfo Sánchez Vázquez, Filosofía de la praxis, loc. cit., p. 273.

4 Ibid., p. 56. Sánchez Vázquez cita los textos siguientes: Antonio Gramsci, "La teoría del materialismo histórico, Manual popular de sociología marxista". En: Antonio Gramsci, El materialismo bistórico y la filosofía de Benedetto Croce. Buenos Aires, Lautaro, 1958, pp. 122-178, original: Il materialismo storico e la filosofia de Benedetto Croce, 8a. ed., Turín, Einaudi, 1966. (Adolfo Sánchez Vázquez, Filosofía de la praxis, loc. cit., p. 52); y Antonio Gramsci, "La revoluzione contro il 'Capitale"'. En: Il grido del popolo, Turín, 5 de enero de 1918; reimpresión en: Rinascita XIV, año núm. 4, abril de 1957 (edición por el XX aniversario de la muerte de Antonio Gramsci, "fundador del PCI, mártir antifascista”, el 27 de abril de 1937, según la portada de Rinascita en aquella época). Adolfo Sánchez Vázquez, Filosofía de la praxis, loc. cit., p. 57.

5 Adolfo Sánchez Vázquez, Filosofía de la praxis, loc. cit., p. 56.

6 Ibid., p. 57.

7 Ibid.

8 Ibid. Además: “[...] Gramsci pretendía subrayar el papel de la actividad práctica revolucionaria en un momento en que la mayor parte de los jefes de la socialdemocracia europea hacía tabla rasa de ella. Pero esta preocupación legítima no debe conducir a una subestimación del papel determinante de los factores objetivos que los oportunistas elevaban al plano de lo absoluto." (Ibid.)

9 Ibid., pp. 57 y ss., nota 36. Sánchez Vázquez se refiere a la crítica de Althusser contra Gramsci en: Louis Althusser et al., Lire le Capital, tomo II, París, Maspero, 1965, pp. 82 y ss., pp. 144-149, pp. 248 y s., y pp. 276 y s. (Adolfo Sánchez Vázquez, Filosofía de la praxis, loc. cit., por ejemplo, pp. 52 y ss.) y a la posición del propio Althusser en: Pour Marx, París, Maspero, 1965, capítulo "Sur la dialectique materialiste", pp. 161-224. Así como: “Teoría, práctica teórica y formación teórica. Ideología y lucha ideológica". En: Casa de las Américas, núm. 34, La Habana, enero de 1966, pp. 5-31, aquí: pp. 13-17. (Firmado: París, 20 de abril de 1965). Traducido al español por Enrique Román. (Sánchez Vázquez, Filosofía de la praxis, loc. cit., p. 52.)

${ }^{10}$ Adolfo Sánchez Vázquez, Filosofía de la praxis, loc. cit., p. 58, nota 36.

${ }^{11}$ Ibid., p. 58.

12 Ibid., pp. 289 y s.

${ }^{13}$ Ibid., p. 290. 
14 Ibid.

15 Ibid., p. 295.

16 Ibid., p. 290.

17 Ibid.

18 Ibid., pp. 290 y s.

${ }^{19}$ Ibid., p. 291. Aquí también resuena la crítica a la concepción de Althusser de la "pratique théorique" como una forma de praxis, entre otras, lo cual abordaremos en el siguiente apartado.

${ }^{20}$ Ibid., 'La dependencia de la teoría respecto de la práctica y la existencia de ésta como fundamento y fin último de la teoría ponen de manifiesto que la práctica — concebida como una praxis humana total— tiene la primacía sobre la teoría, pero este primado suyo, lejos de entrañar una contraposición absoluta a la teoría, presupone una íntima vinculación con ella.” (Ibid.)

${ }^{21}$ Ibid., pp. 292 y ss. Adolfo Sánchez Vázquez menciona aquí el siguiente texto: Kostas Axelos, Marx, penseur de la technique, París, 1961. En particular pp. 254-258. (Adolfo Sánchez Vázquez, Filosofía de la praxis, loc. cit., p. 293, notas 20 y 21.)

22 Adolfo Sánchez Vázquez, Filosofía de la praxis, loc. cit., p. 293. La terminología de Sánchez Vázquez vuelve a mostrar aquí la gran influencia que ha tenido para él la discusión y, al final, la ruptura con la teoría estética del 'realismo socialista'.

${ }^{23}$ Ibid., Sánchez Vázquez se refiere aquí a la octava Tesis sobre Feuerbach, en particular a su última frase, para oponerse a la comprensión de Axelos sobre Marx.

${ }^{24}$ Adolfo Sánchez Vázquez, Filosofía de la praxis, loc. cit., Sánchez Vázquez no entra en el trasfondo político-social de la concepción de Axelos sobre el conocimiento. Aquí ya no entra nuestro autor en las implicaciones epistemológicas exactas de la teoría de Gramsci, con una salvedad: en la crítica de la concepción pragmatista del conocimiento de William James, que Sánchez Vázquez comienza con una crítica de la conciencia cotidiana, menciona a Gramsci brevemente de manera afirmativa, al encomiar la discusión crítica de éste sobre la conciencia cotidiana contemporánea. (Ibid., pp. 270-274, en particular pp. 270 y ss., nota 2).

25 Ibid., p. 294

${ }^{26}$ Karl Marx, El capital. Crítica de la economía política. Libro primero. El proceso de producción de capital, tomo I, vol. 1. Trad. de Pedro Scaron. México, Siglo XXI, 1975, p. 96. Original: Karl Marx, Das Kapital. Kritik der politischen Ökonomie. Erster Band [tomo I7. Buch I: Der Produktionsprozeß des Kapitals. Karl Marx, Friedrich Engels, Werke, tomo 23, Berlin, RDA: Dietz, 1975 , p. 92.

27 Adolfo Sánchez Vázquez, Filosofía de la praxis, loc. cit., p. 293.

28 Karl Marx, Contribución a la crítica de la economía política. (Prólogo). Trad. Jorge Tula, León Mames, Pedro Scaron, Miguel Murmis y José Aricó. México, Siglo XXI, 1980, p. 6.

29 Adolfo Sánchez Vázquez, Filosofía de la praxis, loc. cit.

30 Sobre la crítica de Sánchez Vázquez a la concepción de conocimiento en Althusser, véase en especial los siguientes textos: Ibid., segunda parte: "Algunos problemas en torno a la praxis", capítulo I: "Qué es la praxis", subcapítulo: "La actividad teórica”, y subcapítulo: "Filosofía y praxis", pp. 261-267.

Véase además: Adolfo Sánchez Vázquez, Ciencia y revolución. El marxismo de Althusser, Madrid, Alianza Editorial, 1978, en especial pp. 61-72 y pp. 154-164. También hay una edición más reciente del libro con una entrevista de B. Lima con Sánchez Vázquez como prólogo, además de la correspondencia con Etienne Balibar en el apéndice: Adolfo Sánchez Vázquez, Ciencia y revolución. El marxismo de Althusser. México, Grijalbo, 1983. Sobre la discusión de Sánchez Vázquez con Althusser véase además: Adolfo Sánchez Vázquez, "El teoricismo de Althusser. Notas críticas sobre una autocrítica”. En: Cuadernos Políticos, núm. 3, México, 1975. La única monografía existente sobre Sánchez Vázquez se refiere a la mencionada discusión: Enrique González Rojo, Epistemología y socialismo. La crítica de Sánchez Vázquez a Louis Althusser. México, Diógenes, 1985.

31 Adolfo Sánchez Vázquez, Filosofía de la praxis, loc. cit., p. 261.

32 Ibid.

${ }^{33}$ Ibid.

34 Ibid.

35 Ibid., cursivas de S.G.

36 Ibid.

37 Ibid.

38 Ibid., pp. 261 y s.

${ }^{39}$ Ibid., p. 262.

${ }^{40}$ Ibid., p. 265.

41 Ibid., p. 262.

42 Ibid., p. 263.

43 Ibid., p. 262.

44 Ibid.

45 Véase por ejemplo: "He aquí por qué Hegel cayó en la ilusión de concebir la realidad como resultado del pensamiento que, partiendo de sí mismo, se concentra en sí mismo, profundiza en sí mismo y se mueve por sí mismo, mientras que el método que consiste en elevarse de lo abstracto a lo concreto es para el pensamiento sólo la manera de apropiarse lo concreto, de reproducirlo como un concreto espiritual. Pero esto no es de ningún modo el proceso de formación de lo concreto mismo." 
(Karl Marx, "Introducción general a la crítica de la economía política". En: Karl Marx, Contribución a la crítica de la economía politica, loc. cit., pp. 281-313, I: "Producción, consumo, distribución, cambio (circulación)", 3.: "El método de la economía política" pp. 300-310, aquí: p. 301.)

46 Adolfo Sánchez Vázquez, Filosofía de la praxis, loc. cit.

${ }^{47}$ Ibid.

48 Ibid., p. 294.

${ }^{49}$ Ibid., Pero aquí podemos señalar por nuestra parte que la expresión 'en última instancia', utilizada aquí, muy habitual en la literatura marxista y procedente de Engels, ha conducido una y otra vez a las mayores vaguedades, inexactitudes y confusiones, precisamente en la pregunta, no muy alejada del presente problema, de la 'dependencia de la superestructura respecto a la base'. (Véase: Friedrich Engels, "Engels a José Bloch”, 21/22 de septiembre 1890 [según Der sozialistische Akademiker, Berlín, año 1, núm. 19, 1 de octubre de 1895]. En: Friedrich Engels, Cartas sobre el materialismo histórico, Moscú, Progreso, 1980, pp. 8-10, aquí: p. 8.)

50 Adolfo Sánchez Vázquez, Filosofía de la praxis, loc. cit.

${ }^{51}$ Véase, por ejemplo, ibid., p. 294, nota 22. Sánchez Vázquez se refiere en su crítica general a Althusser, sobre todo a la concepción de Althusser sobre el conocimiento, y cita los siguientes textos: Pour Marx, loc. cit., pp. 167 y 175; L. Althusser et al., Lire le Capital, loc. cit., tomo I, p. 85; y "Teoría, práctica teórica y formación teórica. Ideología y lucha ideológica”, loc. cit., pp. 1317. (Adolfo Sánchez Vázquez, Filosofía de la praxis, loc. cit., p. 263, nota 20.)

52 Adolfo Sánchez Vázquez, Filosofía de la praxis, loc. cit., p. 263, nota 20.

53 Véase: Louis Althusser, "Teoría, práctica teórica y formación teórica. Ideología y lucha ideológica”, loc. cit., (Adolfo Sánchez Vázquez, Filosofía de la praxis, loc. cit., p. 263, nota 20.)

54 Adolfo Sánchez Vázquez, Filosofía de la praxis, loc. cit., p. 263, nota 20.

${ }^{55}$ Ibid., La frase citada va precedida de esta otra:

"Sin embargo, la extensión del término 'práctica' a todo tipo de relación o apropiación del mundo real, incluyendo no sólo la teórica e ideológica, sino también la ética y la religiosa, hace que se borre el carácter esencial de la praxis que Marx justamente pretendió destacar (como transformación efectiva, real, de un objeto real) frente a un 'idealismo de la praxis' (reducción de ésta a la actividad teórica o moral)". (Ibid.)

Recebido em: 02.09.2019

Publicado em: 20.04.2020 